\title{
PRODUÇÃO DE ALFACE EM SISTEMA HIDROPÔNICO EM FUNÇÃO DE MUDAS PRODUZIDAS COM AUXILIO DE ILUMINAÇÃO ARTIFICIAL COMPLEMENTAR
}

\author{
Luis Eduardo Vieira Pinto ${ }^{1}$, Angela Madalena Marchizelli Godinho ${ }^{1}$, Fernando Bernardo Martins ${ }^{2}$. \\ ${ }^{1}$ Faculdade de Tecnologia de Pres. Prudente - FATEC, Curso Superior de Tecnologia em Agronegócio, Presidente \\ Prudente -SP. E-mail: coordenacaovrpp@gmail.com
}

\section{RESUMO}

O cultivo hidropônico ainda é recente no Brasil, dessa forma existe a necessidade da realização de pesquisas na área visando aprimorar as tecnologias utilizadas no seu manejo e buscar novas técnicas para a obtenção de um bom desempenho. O experimento teve como objetivo verificar o ganho de massa no processo produtivo da alface hidropônica em função da utilização de mudas produzidas através do uso de iluminação artificial complementar em diferentes tempos de exposição. O delineamento experimental utilizado foi inteiramente ao acaso, contendo 5 tratamentos com 20 repetições, totalizando 100 unidades experimentais. Os tratamentos constaram de 4 exposições diárias de tempo a luz artificial (2, 3, 4 e 24 horas) e um tratamento controle (sem iluminação artificial - apenas iluminação ambiente). A iluminação artificial foi utilizada durante as fases de desenvolvimento das mudas ( 22 dias). A adição de luz artificial não se mostrou viável para a produção da alface no sistema hidropônico.

Palavras-chave: Lactuca sativa; Estufa; Solução nutritiva; Massa seca; fotomorfogênese.

\section{LETTUCE PRODUCTION SYSTEM HYDROPONIC PLANTS IN FUNCTION PRODUCED WITH ARTIFICIAL LIGHTING SUPPLEMENTARY}

\begin{abstract}
The hydroponics is still new in Brazil, thus there is a need of conducting research in the area aiming to improve the technologies used in their management and seek new techniques to obtain a good performance. The experiment aimed to determine the mass gain in the production process of hydroponic lettuce for the use of seedlings produced through the use of artificial supplementary lighting in different exposure times. The experimental design was completely randomized with 5 treatments with 20 repetitions, totaling 100 experimental units. Treatments consisted of 4 daily exposure time to artificial light (2, 3, 4 and 24 hours) and a control (no artificial lighting - just ambient light) treatment, the artificial lighting was used during the development stages of seedlings ( 22 days). The addition of artificial light was not feasible for lettuce production in the hydroponic system.
\end{abstract}

Keywords: Lactuca sativa; Greenhouse; Nutrition; Dry matter; photomorphogenesis. 
INTRODUÇÃO

A produção de olerícolas é uma atividade agrícola vantajosa quando praticada em condições ambientais e mercados adequados para sua comercialização. Desta forma, é imprescindível a busca de novas alternativas de cultivo e tecnologias que contribuam para o aumento da produtividade (ARAÚJO et al., 2009).

Atualmente, o cultivo de hortaliças em ambiente protegido é muito difundido, devido à possibilidade de controle das condições adversas de cultivo, que favorece o desenvolvimento das plantas e permite a produção de olerícolas de melhor qualidade (HELBEL JÚNIOR et al., 2008). Devido a essa tendência do mercado hortícola, o cultivo protegido (túneis e estufas) vem aumentando em importância a cada ano, assim como o cultivo hidropônico, os quais podem modificar parcial ou totalmente os sistemas de cultivo tradicionais (GUALBERTO et al., 2009).

No Brasil, o cultivo comercial de hortaliças e plantas ornamentais, usando técnicas de hidroponia, é de introdução recente, e vem se expandindo rapidamente nas proximidades dos grandes centros urbanos, onde as terras agricultáveis são escassas e caras e onde há grande demanda por produtos hortícolas. Em tais regiões, a produção de hortaliças é realizada em sua maior parte sob cultivo protegido, caso em que o cultivo hidropônico apresenta-se como alternativa vantajosa. Ciclos de produção mais curtos, possibilidade de uso do espaço vertical na casa de vegetação, maior produtividade, menor necessidade de mão-de-obra, menores riscos de salinização do meio de cultivo e de poluição do lençol freático com nitrato figuram entre as principais vantagens da hidroponia (SANTOS, et al., 2008).

A definição de hidroponia geralmente apresentada nas enciclopédias e dicionários modernos é a de que se trata de uma técnica para se criar plantas sem o uso da terra, alimentando-as com soluções de água e sais minerais (SHOULTO, 2001). Para Alberoni (2008) a hidroponia significa trabalho com a água, sendo uma técnica em que as plantas não entram em contato com o solo e são cultivadas em soluções nutritivas que são produzidas cuidadosamente para nutrir a planta, circulando entre suas raízes.

A alface (Lactuca sativa L.) é a hortaliça folhosa de maior valor comercial cultivada no Brasil, com cerca de setenta e cinco cultivares comerciais, das quais, aproximadamente dezoito são nacionais. É considerada planta de propriedades tranquilizantes, com alto conteúdo de vitaminas A, B e C, além de cálcio, fósforo, potássio e outros minerais (FILGUEIRA, 2000). Segundo SANTOS et al., (2008), a alface é a hortaliça folhosa mais consumida no Brasil, sendo considerada a base das saladas. 
A alface é uma planta típica de países que apresentam temperaturas mais amenas. Sendo a principal hortaliça do consumidor brasileiro, pesquisas com melhoramento genético (FELTRIN et al., 2005) e cultivo em ambiente protegido (OTTO et al., 2001) possibilitaram seu cultivo em todas as épocas do ano, ampliando a oferta no mercado em épocas de escassez e possibilidade de obtenção de melhor preço.

O uso da iluminação artificial para plantas oferece grandes vantagens, já que ela pode ser manipulada e controlada pelo homem de acordo com as necessidades das plantas, observando os períodos de luz e escuro, fazendo com que elas respondam a estímulos luminosos específicos. É possível monitorar adequadamente a intensidade, a qualidade e a quantidade de luz para determinadas situações (NUNES, 2013).

Altamente sensíveis à luz, as plantas são extremamente dependentes e dela tiram sua sobrevivência. A radiação luminosa é fonte de energia para as plantas e estimula o seu desenvolvimento, podendo também se tornar um fator de estresse. Mesmo respondendo a mesma faixa de comprimento de onda da luz visível ao olho humano, as plantas absorvem essa energia de forma diferente e a sintetiza em seu benefício (MARTINS, 2013).

O experimento teve como objetivo verificar o ganho de massa no processo produtivo da alface em uma horta com sistema hidropônico do tipo fluxo contínuo de nutrientes, utilizando a iluminação artificial para verificar sua viabilidade de utilização na prática da hidroponia.

\section{METODOLOGIA}

O experimento foi implantado no decorrer de 43 dias no período de 26 de março a 07 de maio de 2015 em estufa de produção comercial de alface mimosa localizada no município de Pirapozinho - SP.

O delineamento experimental utilizado foi inteiramente ao acaso, contendo 5 tratamentos com 20 repetições, totalizando 100 unidades experimentais. Os tratamentos constaram de 4 exposições diárias de tempo à luz artificial ( 2 horas, 3 horas, 4 horas e 24 horas) e uma testemunha (sem iluminação artificial "0 horas” - apenas iluminação ambiente).

Para o sistema hidropônico, a produção das mudas deve ser realizada em espuma fenólica, assim como se procedeu neste experimento. Utilizou-se sementes peletizadas de alface mimosa com pureza física de 99,9\% e índice de germinação de 93\%. As espumas foram cortadas e divididas em blocos com 20 células cada, após a divisão as espumas foram lavadas para a retirada de impurezas e após a lavagem efetuou-se os orifícios (células) para a semeadura da alface. A semeadura foi realizada utilizando uma semente por célula. 
Após a semeadura, a espuma fenólica foi umedecida e colocada em ambiente sem incidência de luz solar direta ou artificial por 48 horas para iniciar a germinação. Após as 48 horas, as mudas germinadas foram colocadas sob a incidência de luz artificial no qual utilizou-se 8 lâmpadas LED do tipo Grow-lux (vermelho e azul) de 3W, a distribuição era feita de forma a ficar 2 lâmpadas por tratamento, no qual cada lâmpada era composta por 60 LEDs (15 de coloração azul visando o estimulo do crescimento inicial e 45 de coloração vermelha visando a indução do crescimento vegetativo). Dessa forma, foram estabelecidos os tempos definidos de cada tratamento $(2,3,4,24$ horas e 0 horas - testemunha), por um período de 7 dias, mantendo-se irrigação uniforme durante esse período.

Após o período de germinação as mudas foram colocadas nos perfis de hidroponia (perfis de mudas que antecedem a fase de desenvolvimento final da alface) que possuíam o espaçamento de $10 \mathrm{~cm}$ entre plantas. A partir desse momento as mudas passaram a receber a adição de solução nutritiva Hidrogood Fert durante um período de 15 dias e continuaram recebendo a exposição de iluminação artificial diariamente durante esse período. A exposição à iluminação artificial no período de 2, 3 e 4 horas para ambas as etapas eram realizadas diariamente partir das 18h30m, período esse no qual a iluminação natural na estufa era menor.

Passado o período de permanência de 15 dias nos perfis de mudas, as plantas foram transplantadas para os perfis de desenvolvimento que possuem espaçamento de $20 \mathrm{~cm}$ entre plantas. Para essa fase foram cessados o uso da iluminação artificial. Aos 19 dias após o transplantio para os perfis de desenvolvimento, as plantas foram coletadas para a realização das análises em laboratório.

Após a lavagem das plantas, as mesmas foram colocadas em sacos de papel Kraft e levadas para a estufa de circulação de ar forçado, por onde permaneceram durante um período de 72 horas mantendo-se a temperatura na faixa de $65^{\circ}-70^{\circ} \mathrm{C}$. Após a secagem do material realizou-se um corte na região do colo da planta para seccionar a raiz e parte aérea para posterior pesagem.

Todos os dados foram submetidos à análise de variância (ANOVA, $p<0,05$ ) e ao teste de comparação de médias Tukey $(p<0,05)$, através do pacote estatístico Assistat (SILVA, 2011). 


\section{RESULTADOS}

Tabela 1. Resultados das análises estatísticas das variáveis analisadas "massa seca da raiz (MSR) e massa seca da parte aérea (MSPA)".

\begin{tabular}{lcc}
\hline TRATAMENTOS (ILUMAÇÃO DIÁRIA) & MSR (g) & MSPA (g) \\
\hline Testemunha & $1,79 \mathrm{a}$ & $10,01 \mathrm{a}$ \\
2 horas & $1,70 \mathrm{a}$ & $7,97 \mathrm{~b}$ \\
3 horas & $1,63 \mathrm{a}$ & $7,63 \mathrm{~b}$ \\
4 horas & $1,75 \mathrm{a}$ & $8,47 \mathrm{~b}$ \\
24 horas & $1,71 \mathrm{a}$ & $9,46 \mathrm{a}$ \\
\hline MÉDIAGERAL & 1,72 & 8,71 \\
\hline CV (\%) & 21,33 & 17,78 \\
\hline
\end{tabular}

Médias seguidas de mesma letra não diferem estatisticamente pelo teste de Tukey (5\%)

\section{DISCUSSÃO}

De acordo com os resultados estatísticos das variáveis analisadas no experimento expressos na tabela 1, observa-se que para a variável massa seca da raiz (MSR) não houve diferença estatística significativa entre os tratamentos avaliados pelo experimento, demonstrando que o sistema radicular das plantas não sofreu alteração em sua biomassa pela ação direta da iluminação artificial. Já para a variável massa seca da parte aérea (MSPA) nota-se que o tratamento testemunha (sem iluminação artificial - apenas iluminação ambiente) e o tratamento com 24 horas de iluminação artificial promoveram um desenvolvimento mais acentuado da biomassa da alface, resultando em maior ganho de massa, sendo os mesmos superiores aos demais tratamentos avaliados no experimento. Os resultados encontrados no experimento contrapõem os resultados de Pascale e Damario (2004), os quais afirmam que a iluminação artificial, por aumentar o fotoperíodo, tem efeito fotoestimulante, exercendo importante papel no desenvolvimento vegetal. Também Terzaghi e Cashmore (1995) afirmam que o fitocromo tem um importante papel no desenvolvimento vegetativo e reprodutivo regulado pela luz.

Os resultados obtidos também divergem dos encontrados por Maluf et al. (2012), que utilizando a iluminação artificial complementar em alface, concluíram as luzes de coloração azul, vermelha e branca elevaram as características agronômicas da cultura da alface significativamente quando comparado com o tratamento testemunha. Cavichioli et al. (2006) observou que o uso de iluminação prolongando o fotoperíodo favoreceu o surgimento de flores na cultura do maracujazeiro, também contradizendo com os resultados obtidos no experimento. Como hipótese, acreditamos que talvez se a iluminação artificial fosse utilizada durante todo o período 
de desenvolvimento da alface hidropônica, incluindo a etapa realizada nos perfis de desenvolvimento, os resultados obtidos poderiam se assemelhar aos citados pelos autores acima.

\section{CONCLUSÃO}

O uso da iluminação artificial diária inferior ao período de 24 horas não promoveu o maior ganho de massa da alface.

\section{REFERENCIAS}

ALBERONI, R. DE B. Hidroponia: como instalar e manejar o plantio de hortaliças dispensando o uso de solos. Rio de Janeiro: NBL Editora, 2008.

ARAúJO, J. S.; ANDRADE A. P. De.; RAMALHO, C. I.; AZEVEDO, C. A. V. de. Características de frutos de pimentão cultivado em ambiente protegido sob doses de nitrogênio via fertirrigação. Revista Brasileira de Engenharia Agrícola e Ambiental, v.13, p.152-157, 2009. http://dx.doi.org/10.1590/S1415-43662009000200007

CAVICHIOLI, J. C.; RUGgIERO, C.; VOlPE, C. A.; PAULO, E. M.; FAGUNDES, J. L.; KASSAI, F. S. Florescimento e frutificação do maracujazeiro-amarelo submetido à iluminação artificial, irrigação e sombreamento. Rev. Bras. Fruticultura, Jaboticabal - SP, v. 28, n. 1, p. 92-96, Abril 2006.

FILGUEIRA, F.A. R. Novo manual de olericultura: agrotecnologia moderna na produção e comercialização de hortaliças. Viçosa: UFV, 2000. 402p. : p. 40 - 135, 288 - 295.

FELTRIM, A.L.; CECÍLIO FILHO, A.B.; BRANCO, R.B.F.; BARBOSA, J.C.; SALATIEL, L.T. Produção de alface-americana em solo e em hidroponia, no inverno e verão, em Jaboticabal - SP. Revista Brasileira de Engenharia Agrícola e Ambiental, Campina Grande, v.9, n.4, p.505-509, 2005. http://dx.doi.org/10.1590/S1415-43662005000400010

HELBEL JÚNIOR, C. REZENDE, R.; FREITAS, P. S. L. DE; FRIZZONE, J. A. Influência da condutividade elétrica, concentração iônica e vazão de soluções nutritivas na produção de alface hidropônica. Ciência e Agrotecnologia, v.32, p.1142-1147, 2008. http://dx.doi.org/10.1590/S141370542008000400016

GUALBERTO, R.; OLIVEIRA, P. S. R.; GUIMARAES, A. M. Adaptabilidade e estabilidade fenotípica de cultivares de alface do grupo crespa em cultivo hidropônico. Horticultura Brasileira, Brasília, v. 27, n. 1, p. 7-11, 2009. http://dx.doi.org/10.1590/\$0102-05362009000100002

MALUF, G. E. G. M.; PAULA, A. C. C. F. F.; AlVARenGA, A. A.; MALUF, H. J. G. M. Efeito da iluminação noturna complementar a $18 \mathrm{~cm}$ de altura no crescimento de mudas de alface (Lactuca sativa L.). IV Semana de Ciência e Tecnologia do IFMG campus Bambuí, IV Jornada Científica. Bambuí, 2012.

MARTINS, R. V. Iluminação artificial na hidropônia. Revista online Campo e Negócio 2013. <http://www.revistacampoenegocios.com.br/wpcontent/uploads/2014/07/ILUMINA\%C3\%87\%C3 \%830-ARTIFICIAL-NA-HIDROPONIA.pdf/>. 
NUNES, T. V. F. Luz para plantas. Revista online IPOG ESPECIALIZE 2013.< www.ipog.edu.br/aluno/revista-ipog/download/luz-para-plantas/>.

OTTO, R.F.; REGHIN, M.Y.; SÁ, G.D. Utilização do 'não tecido' de polipropileno como proteção da cultura de alface durante o inverno de Ponta Grossa - PR. Horticultura Brasileira, Brasília, v.19, n.1, p.49-52, 2001. http://dx.doi.org/10.1590/S0102-05362001000100010

PASCALE, A.J.; DAMARIO, E.A. Bioclimatologia agrícola e agroclimatologia. Buenos Aires: Editorial Facultad Agronomia, 2004. 550p

SANTOS, A. O.; NETO, B. L. R.; ZWIRTES, D. S.; SILVA, R. B. DA.; YONENAGA, W. H. Produção de alface hidropônica: uma abordagem pela dinâmica de sistemas. Anais do 4 Congresso Brasileiro de Sistemas - Centro Universitário de Franca Uni-FACEF - 29 e 30 de outubro de 2008.

SILVA, F. de A. S. Assistat Software - Assistência Estatística. Versão 7.6 beta (2011). Disponível em http://www.assistat.com/indexp.html.

SHOULTO, D. J. Hidroponia: cultura sem terra. Rio de Janeiro: NBL Editora, 2001.

TERZAGHI, W. B.; CASHMORE, A. R. Light-Regulated Transcription. Annu. Rev. Plant Physiol. Plant Mol. Biol. 46, 1995. http://dx.doi.org/10.1146/annurev.pp.46.060195.002305 